\title{
Attitudes of Non-native Speakers of English Studying in Australia towards World Englishes
}

\author{
Aditya Nur Patria \\ Applied Foreign Language Department \\ Vocational College \\ Universitas Diponegoro, Semarang, Indonesia
}

Received: 3/30/2021 Accepted: 5/18/2021 Published:6/24/2021

\begin{abstract}
The present study explores attitudes of non-native speakers of English studying in a reputable university in Melbourne, Australia, towards world Englishes. In particular, the study investigates different attitudes between students enrolled in a university subject, which indirectly promotes the students' acceptance towards them and those who have not taken the subject towards world Englishes. The present study uses the direct approach, which allows informants to give an account of their attitudes (McKenzie, 2010). By adopting a questionnaire designed by Yoshikawa (2005), the present study seeks to answer two research questions: (1) Do non-native English students taking the subject have different attitudes from non-native English students who have not taken the subject towards world Englishes? (2) Do the students enrolled in LinguisticRelated majors have different attitudes from the students enrolled in Non-Linguistic-Related majors towards world Englishes? The findings of the study will contribute to the literature on world Englishes and the identification of a possible way to promote the acceptance of world Englishes. The results show that informants who are taking/have taken the subject tend to have more positive attitudes towards non-Inner Circle varieties than those who have not taken the subject. Similar results are also shown among informants grouped based on their majors in which Linguistics-Related ones are more acceptant. However, there is no significant difference regarding their attitudes toward Inner Circle English.
\end{abstract}

Keywords: Australia, language attitude, language variations, native speakers, non-native speakers of English, world Englishes

Cite as: Patria, A.N. (2021). Attitudes of Non-native Speakers of English Studying in Australia towards World Englishes. Arab World English Journal, 12 (2) 294-305.

DOI: https://dx.doi.org/10.24093/awej/vol12no2.20 


\section{Introduction}

\section{Background of the Study}

Several researchers (e.g., Crystal, 2003; Yano, 2009) mentioned English as the most taught foreign language in the world. This means that English is used by many non-native speakers of English (NNSEs). Hence, NNSEs who use English for communication arguably outnumber the native speakers of English (NSEs). However, English language varieties taught to EFL students are still limited to those of Inner Circle, i.e. Standard American English and Standard British English (Dewi, 2014; Lippi-Green, 2012).

Many English language courses rely heavily on Inner Circle English. This may cause NNSE students to be unaware of and unfamiliar with other varieties of English such as Singaporean English, Indian English, and many others (da Rosa, 2017). Furthermore, this makes them think that Inner Circle English is the only legit way to speak English (Ferguson, 1992; Marlina, 2013). However, some programs in higher education, especially of linguistics-related majors, offer a subject that allows the students to be more aware of different varieties of English around the world. The subject usually opens a discussion that focuses on the issues of world Englishes. This subject is also offered in an Australian university.

Australia is among the top destinations for international students to earn their degrees. According to Australia's Department of Education and Training (2018), international students made up $27 \%$ of students in the country. With a considerable number of international students, maintaining respect for diversity is necessary. In a reputable university in Melbourne, Australia, there is a subject that explores the relationship between sociolinguistics and second language learning (hereafter referred to as SSLL). The subject is available for students enrolled in linguistic-related Master's programs, including Applied Linguistics, TESOL, and Education. Although not stated explicitly in the subject guidelines, the subject indirectly raises students' awareness of different varieties of English and promotes acceptance towards them.

The present study would like to see to what extent the subject contributes to promoting acceptance towards diverse English variations. Increasing the acceptance towards world Englishes is necessary to elevate the confidence of non-native variety of English users and to discourage any discriminatory actions against them (Almegren, 2018; McKenzie, 2010). It is expected that the present study can add to the literature of world Englishes and provide insights of a way of increasing people's acceptance to world Englishes. Thus, the present study attempts to identify the different attitudes towards world Englishes among NNSE students who are taking the subject and those who have not taken the subject. It is also important to note that the discussion about world Englishes in the university for students of Linguistic-Related (LR) majors may not be restricted only in SSLL class. Other subjects in LR majors also address world Englishes although not as intensive as in SSLL class. Thus, the present study also attempts to investigate whether exposure to such issues in LR majors is a contributing factor in the students' attitudes towards world Englishes. In order to do that, the present study investigates the different attitudes towards world Englishes among students in LR majors and students in Non-LinguisticRelated (NLR) majors. In brief, some research questions the present study attempt to investigate are as follows:

1. Do NNSE students taking SSLL subject have different attitudes from NNSE students who have not taken SSLL subject towards world Englishes? 
2. Do NNSE students enrolled in LR majors have different attitudes from NNSE students enrolled in NLR majors towards world Englishes?

Based on the research questions formulated above, the objectives of the present study are as follows.

1. To identify whether or not NNSE students taking SSLL subject have different attitudes from NNSE students who have not taken SSLL subject towards world Englishes

2. To identify whether or not students in LR majors have different attitudes from students in NLR majors towards world Englishes

\section{Literature Review World Englishes}

The idea of World Englishes was introduced by Kachru (1985). The term itself uses a plural noun to acknowledge the diverse varieties of English developed outside the Inner Circle countries. The term "Inner Circle" was used as he categorized English varieties into three circles, i.e., Inner, Outer, and Expanding Circles. Inner Circle constitutes countries where English is originated and is widely spoken as the native language by the community, such as the US, UK, Australia, and New Zealand. Outer Circle refers to "postcolonial Anglophonic contexts, a numerically large and diverse community" (Bolton, 2009, p.292) where English holds status as an official language. Countries that are considered in Outer Circle include Singapore, India, and Nigeria. Expanding Circle represents countries where English is generally considered a foreign language, such as Japan, Indonesia, China, Vietnam, and Thailand. Although some scholars (e.g., Al-Mutairi, 2020; Bruthiaux, 2003; Mollin, 2006) have criticized this model for promoting specific varieties and oversimplifying the diverse use of English in different regions, the classification itself demonstrates acknowledgment of the myriad varieties of English across the globe.

\section{Language Attitudes towards World Englishes}

The issues related to language attitudes towards world Englishes have gained more attention among linguists over the years. Negative attitudes towards non-native varieties of English have caused misunderstandings about the ownership of English (Ferguson, 1992). Although English is widely used as an international language, some NNSEs still believe that NSEs are the better users of the language and some English-related professions (e.g., English teacher) are better done by NSEs (Amin, 1997; Medgyes, 1992), not to mention that such issue was also found in languages other than English (e.g. Tsuchiya, 2020). Such fallacy has been challenged by some scholars (e.g., Medgyes \& Kiss, 2019; Phillips, 2017; Phillipson, 1992; 1996) who argued that one's language background is not the primary factor of one's language teaching skills. Inner Circle Englishes is undoubtedly dominant in language courses (Tan, 2005; Ulum \& Köksal, 2019). However, some scholars (Gerritsen \& Nickerson, 2009; Mahboob \& Elyas, 2014) have suggested that introducing other varieties is necessary in the globalized era, in which people meet not only with NSEs. Some efforts have been done to increase the awareness and acceptance of world Englishes, one of which is by using authentic materials of world Englishes in ESL/EFL classes (Marlina, 2013; Matsuda, 2003; Passakornkarn \& Vibulphol, 2020).

Some scholars (e.g., Almegren, 2018; Kim, 2007; Yoshikawa, 2005) have specifically studied the perception of NNSEs towards world Englishes. They investigated the perception of 
NNSE students in Expanding Circle countries towards world Englishes. Yoshikawa (2005) and McKenzie (2010) examined the different attitudes of university students in Japan towards varieties of English using questionnaires. Yoshikawa (2005) divided the students from the Department of World Englishes at Chukyo University based on their length of study at the university. The results showed that the second- and third-year students are more acceptant towards a variety of English from their country, i.e., Japanese English. However, the longer their length of study was, the more they preferred Inner Circle English over Outer Circle as a model. His study also addressed the issues related to the ownership of the language and the legitimacy of NNSEs as English teachers. On the other hand, McKenzie (2010) also focused on the students' awareness of different varieties of English by using verbal guise tests. The results showed that the students were unable to recognize non-standard varieties of English from Europe. Similar to Yoshikawa's study, the students were more reliant to the Inner Circle varieties for the language model. He also found that the students tended to perceive Japanese-accented English to have "little intrinsic value or status and that assimilation to the prestige varieties (i.e., "native speaker Englishes') is the most desirable outcome" (McKenzie, 2010, p. 147). This, in part, illustrates the inability to accept non-native varieties of English.

A study conducted by Kim (2007) in South Korea focused on language attitudes towards world Englishes among Korean adult learners. Similar to Yoshikawa and McKenzie's studies, Kim found that the participants preferred American English as a model and regarded English as a means of communication to interact not only with NSEs but also NNSEs. Interestingly, though they showed positive attitudes to non-native varieties of English, they were not well aware of different varieties of English. In other words, the participants apparently "regarded English as an international language and do not discriminate native and non-native varieties/models of English" (Kim, 2007, p.42). Furthermore, some participants were interested in learning nonnative varieties of English, especially those of Outer Circle. Most of the participants also showed positive attitudes towards local teachers teaching English, likely because of the shared culture and language.

A more recent study was undertaken by Almegren (2018) in Saudi Arabia. He investigated 50 Saudi students' awareness and acceptance towards non-native varieties of English. The data collection was incorporated with interviews with some participants. The results showed that the participants were aware of different varieties of English. However, unlike Kim's study, Almegren's study brought up an issue of legitimate speakers of English. This has caused them to have a lack of confidence about their accents, meaning that they were not likely to accept the variety of English of their nation. As Almegren (2018, p. 244) pointed out, most participants "were not impressed by their accent irrespective of the fact that they were speaking correctly." Based on the results, the participants preferred American English as the various model and English native speakers as their English language teachers.

Some studies demonstrated mixed results with regards to the NNSEs' perceptions towards world Englishes. However, all of them showed that conducting a survey using Likertscale questionnaires provides fruitful insights for language attitude research. It is important to highlight that none of these studies were undertaken in an Inner Circle country. Hence, the present study tries to fill the gap by undertaking the research among international NNSE students in Australia. As Australia has attracted many international students from different countries, it is 
inevitable for these students to interact with people from different countries and be exposed to different varieties of English. Furthermore, the present study focused on SSLL as a contributing factor to the students' acceptance of world Englishes.

\section{Methods}

The present study used the direct approach to investigate informants' language attitudes. According to McKenzie (2010), the direct approach allows the informants to provide an account of their attitudes. The informants easily understand what they need to do in the study, making the data collection less time-consuming. In order to measure the informants' language attitudes, the present study uses questionnaires that will elicit quantitative data. Quantitative data analysis allows the researcher to draw a general conclusion from a larger sample size (Agheyisi \& Fishman, 1970; Rahman, 2017). Another advantage of quantitative data analyses is that the data can be easily categorized according to the objective of the research (McKenzie, 2010; Almegren, 2018). The details of the study methods are as follows.

\section{Informants}

The present study uses convenience sampling. This type of sampling is chosen because it allows the researcher to recruit members of the target population with specific practical criteria, including easy accessibility, their availability, and willingness to participate (Dörnyei, 2007). Informants in this study consist of 29 students of Master's programs at the reputable university in Melbourne, Australia in May 2017: 13 students were taking/had taken SSLL subject and 16 students did not. The distribution of the students in these categories is relatively equal. There are 17 students from linguistic-related majors (i.e., Applied Linguistics and TESOL) and 12 students from non-linguistic-related majors (i.e., Information Systems, Tax, Development Studies, Law, Public Health, Engineering Management, Urban Planning, and Public Policy). All participants are from Expanding Circle countries, including China, Indonesia, Japan, Saudi Arabia, Malaysia, Vietnam, Cambodia, Pakistan, and Mongolia. Among these participants, $28 \%$ of them have visited English-speaking countries other than Inner Circle countries, meaning that they were likely to have exposure to non-Inner Circle varieties.

\section{Instruments}

The data in the present study were collected using questionnaires. Agheyisi and Fishman (1970) mention that open question questionnaires and closed question questionnaires are among the most widely used instruments to identify ones' language attitudes. Questionnaires with open question items may elicit extensive data, including the ones that researchers may not have anticipated. While researchers can benefit from abundant data, they may need extra time to categorize the responses, rate them, and analyze them. In other words, scoring problems are the main issues in using open question questionnaire in studies on language attitudes. Such disadvantages have caused some researchers to avoid the use of open question questionnaires for an initial survey. Hence, closed question questionnaires are usually preferred in this circumstance. This type of questionnaire is more straightforward by providing the informants with specific responses, usually a set of rating terms such as "yes/no" response or a 5-point scale.

The questionnaire used in the present study is a closed question questionnaire. It adopts the questionnaire designed by Yoshikawa (2005). It uses a 5-point Likert scale, with the value of one point for "strongly disagree" and five for "strongly agree." In other words, the higher the 
value is, the more the participants agree with the statements. Provided that the participants are currently studying at an English-medium university, they are assumed to understand English. Therefore, the questionnaires were written in English. The statements used in the questionnaires were slightly modified from the original version (cf. Yoshikawa, 2005) to adjust with the various backgrounds of the informants and make the statements just.

Statement one seems to be general (see Appendix A). However, it is put in the questionnaires to identify the informants' attitudes towards English as an international language. On the other hand, statements two, three, four, five, six, and seven are used to identify the informants' attitudes towards world Englishes. These statements address not only the language variations, but also the language users (e.g., statements two, three, and seven). A higher value for statements three, five, and six suggest acceptance of the world Englishes. Conversely, a higher value for statements two and four indicates reliance on Inner Circle varieties of English.

In addition to describing the informants' language attitudes, the questionnaire collects participants' background information. The information collected through the questionnaires includes country of origin, study program, whether the informants are taking or have taken SSLL subject, whether or not the informants have visited English-speaking countries other than Inner Circle countries.

\section{Procedures}

Data collection was conducted in May 2017. The questionnaires were distributed in several occasions. The questionnaires were distributed before the week-10 class of SSLL started. This was intended to gather the data from target informants, i.e., those who are taking or have taken SSLL subject. The decision to collect the data in week-10 class was because $75 \%$ of the subject materials in the semester was already taught by week 10, and the students were assumed to have a sufficient understanding of world Englishes. The questionnaires were also distributed to collect data from LR students who have not taken SSLL. In order to get data from students of NLR majors, data collection was done among members of a postgraduate student club at the university.

Following the data collection, the quantitative data collected from the questionnaires were then computed in SPSS Version 24. Similar to that in some studies (Almegren, 2018; Kim, 2007; McKenzie, 2010; Yoshikawa, 2005), the data based on the scale were treated as interval data. In order to answer the research questions, the data were analysed using the independent $t$ test. Furthermore, the effect size was computed using effect size calculator on http://www.uccs.edu/ lbecker/.

\section{Results}

\section{Language Attitudes Based on Enrolment in SSLL Subject}

Based on descriptive statistics as presented in Table one, the group of informants who are taking or have taken SSLL subject has a higher mean value for statements three, five, and six than the group of informants who has not taken the subject do. On the other hand, the informants who have not taken SSLL subject consistently have higher mean value for statements indicating reliance on Inner Circle Englishes, i.e., statements two and four. Furthermore, the mean values are above three, indicating their positive attitudes. Interestingly, the higher mean value for 
statement seven is obtained by informants who have not taken SSLL subject. Despite the difference on descriptive statistics, the results of $t$-test show that the significant difference resides on statements two $(t=2.84, p<0.01, d=1.07)$ and five $(t=3.65, p<0.005, d=1.37)$ only. Furthermore, the results of Cohen's $d$ calculation indicate that effect sizes for the two statements are relatively large. It means that there is a big difference between the two groups towards both statements.

Table 1. Comparison of language attitudes based on enrolment in SSLL subject

\begin{tabular}{|c|c|c|c|c|c|}
\hline & \multicolumn{4}{|c|}{ SSLL enrolment } & \multirow{3}{*}{$t$} \\
\hline & \multicolumn{2}{|c|}{ Yes } & \multicolumn{2}{|c|}{ No } & \\
\hline & Mean & $S D$ & Mean & $S D$ & \\
\hline 1. Importance of learning English & 3.46 & 1.39 & 4.19 & .83 & 1.65 \\
\hline 2. Teaching by NSE & 2.31 & .85 & 3.31 & 1.01 & $2.84 *$ \\
\hline 3. Teaching by NNSE & 2.77 & .93 & 2.56 & .81 & .64 \\
\hline 4. Varieties of Inner Circle & 3.31 & 1.25 & 4.00 & 1.09 & 1.59 \\
\hline 5. Varieties of Outer Circle & 2.38 & .77 & 1.44 & .63 & $3.65 * *$ \\
\hline $\begin{array}{l}\text { 6. Varieties of home country } \\
\text { (Expanding Circle) }\end{array}$ & 4.23 & .72 & 4.00 & .63 & .91 \\
\hline 7. Avoiding idiomatic expressions & 3.00 & .91 & 3.31 & 1.01 & .86 \\
\hline
\end{tabular}

Note. ${ }^{*} p<0.01,{ }^{*} p<0.005, S D=$ Standard Deviation

\section{Language Attitudes based on Majors}

Table two indicates that the group of informants from LR majors have a higher mean value than the group of informants from the NLR majors for statements three, five, and six. It should be noted that except for statement six, the LR group's mean values for statements three and five are lower than three, despite being higher than those of the NLR group. On the other hand, the students from the NLR majors have a higher mean value for statements one, two, four, and seven. In addition, the mean values of the NLR group in these four statements are higher than three, suggesting positive attitudes.

In accordance with $t$-test results, both groups only have significant differences in three statements, i.e. statements two $(t=3.71, p<0.005, d=1.38)$, five $(t=4.19, p<0.001, d=1.65)$, and seven $(t=2.53, p<0.05, d=.96)$. As indicated by the value of Cohen's $d$, the two groups have big differences in their attitudes on the three statements.

Table 2. Comparison of language attitudes based on majors

\begin{tabular}{|l|l|l|l|l|c|}
\hline \multirow{2}{*}{} & \multicolumn{4}{|c|}{ Majors } & \multirow{2}{*}{$t$} \\
\cline { 2 - 5 } & \multicolumn{2}{|c|}{ Linguistics } & \multicolumn{2}{c|}{ Non-linguistics } & \\
\cline { 2 - 5 } & Mean & \multicolumn{1}{|c|}{ SD } & Mean & SD & 1.20 \\
\hline 1. Importance of learning English & 3.65 & 1.32 & 4.17 & .83 & $3.71^{* *}$ \\
\hline 2. Teaching by NSE & 2.35 & .76 & 3.58 & 1.00 & .81 \\
\hline 3. Teaching by NNSE & 2.76 & .90 & 2.50 & .80 & 1.88 \\
\hline 4. Varieties of Inner Circle & 3.35 & 1.11 & 4.17 & 1.20 & $4.19^{* * *}$ \\
\hline 5. Varieties of Outer Circle & 2.29 & .77 & 1.25 & .45 & 1.27 \\
\hline $\begin{array}{l}\text { 6. Varieties of home country (Expanding } \\
\text { Circle) }\end{array}$ & 4.23 & .66 & 3.91 & .67 & $2.53^{*}$ \\
\hline 7. Avoiding idiomatic expressions & 2.82 & .88 & 3.67 & .89 & 2 \\
\hline
\end{tabular}


Note. ${ }^{*} p<0.05, * * p<0.005, * * * p<0.001 S D=$ Standard Deviation

\section{Discussion}

According to the statistical analysis, the informants who are taking or have taken SSLL subject have different attitudes from those who have not taken SSLL towards world Englishes. They have notably different attitudes towards the English teaching by NSEs and varieties of Outer Circle as model languages. It is evident in the data that the informants who have not taken SSLL show a more positive attitude towards NSEs as legitimate English teachers. This attitude may be due to the belief that NSEs have more legitimate ownership of English than NNSEs do (Ferguson, 1992). However, this might also be affected by the qualifications of NSE teachers who were better equipped with a lot of training (Almegren, 2018). The phenomena of native speaker fallacy have also been recorded by some scholars (e.g., Amin, 1997; Medgyes, 1992; Tsuchiya, 2020). On the other hand, SSLL students' attitude towards NSEs as the legitimate English teachers tends to be negative. It is probably due to the learning materials they have learned in the subject (e.g. Rampton, 1990; Widdowson, 1994) that question English ownership. This may lead them to be more critical towards NSEs.

On the other hand, the SSLL students have a higher positive attitude towards Outer Circle English as a model language than non-SSLL students do. The SSLL students are likely to be aware of different varieties of English, and their positive attitude has, in part, shown their acceptance of English varieties other than Inner Circle ones. Unlike Kim's finding (2007) where the learners accepted Outer Circle as a language model because they wanted to visit the country, the SSLL students' awareness is likely affected by the knowledge they got from the subject. This finding is also slightly different from some studies (e.g., Marlina, 2013; Matsuda, 2003; Passakornkarn \& Vibulphol, 2020) which showed the development of ones' awareness through the exposure of authentic materials of world Englishes. It should be noted that the SSLL students may not fully accept Outer Circle varieties as model languages provided the mean value below three. Instead, both SSLL students and those who have not taken the subject equally agree that Inner Circle varieties are suitable as a model language in English learning. This is indicated by the mean value higher than 3. Such finding has also been documented by other scholars (Almegren, 2018; Kim, 2007; McKenzie, 2010; Yoshikawa, 2005) in which the participants mostly favored Standard American English as a preferred language model. This preference could be related to the fact that Inner Circle varieties are dominant in education setting and become the standard (Tan, 2005; Ulum \& Köksal, 2019), although some scholars (Gerritsen \& Nickerson, 2009; Mahboob \& Elyas, 2014) have proven that in real-life communication NNSE users do not necessarily follow Inner Circle English's norms.

When the informants were grouped based on the relatedness of their majors with linguistics, different attitudes towards world Englishes were apparent. The informants from LR majors and NLR majors have different attitudes towards NSE speakers as legitimate English teachers, Outer Circle English as a model language, and avoidance of idiomatic expressions. Similar to the results from SSLL students, the informants from LR majors have a more negative attitude towards NSEs as the legitimate English teachers and a more positive attitude towards Outer Circle English as a model language. It should be noted that some LR informants have not taken SSLL subject. This similar trend of attitudes with that of SSLL informants may be due to the exposure to knowledge of world Englishes they receive in other subjects. Though some 
subjects in LR programs do not necessarily focus on world Englishes, they address some issues on world Englishes. The LR students' career aspirations may contribute to the lower mean score towards NSEs as the legitimate English teachers. Some linguistics or TESOL students may aspire to be English teachers. Thus, they may consider themselves as legit English teachers. As some scholars have argued (e.g., Medgyes \& Kiss, 2019; Phillips, 2017; Phillipson, 1992; 1996), the ability to teach English should not be affected by the fact that one is a native speaker of the language; rather, one's pedagogical skills.

On the other hand, the informants from NLR majors tend to agree to avoid idiomatic expressions. While Yoshikawa (2005) argues that the avoidance of idiomatic expressions shows the tendency to recognize world Englishes, the finding in the present study should be interpreted differently. The attitude towards avoidance of idiomatic expressions is more related to NNSEs' English language proficiency. Because the data were taken in Australia, an Inner Circle country, a higher positive attitude towards avoidance of idiomatic expressions indicates that the informants tend to sympathize with, or underestimate, NNSEs' English competence. They may be worried if the NNSEs do not understand the idiomatic expressions they use, which might lead to miscommunication.

Another thing that comes up in the results of the study is the fact that most informants accept the English variety from their home countries. This finding is different from that in Almegren's (2018) and McKenzie's (2010) studies in which the participants tended to belittle the varieties of their home countries. The loyalty towards home-country varieties is shown by the majority of the informants regardless of their enrolment in SSLL and LR majors. Such attitudes maybe because they are exposed to different varieties every day when they interact with fellow international students. As long as the communication is easily transmitted among the speakers, it should not be a problem for them to accept any English varieties.

\section{Conclusion}

The present study seeks to answer different attitudes towards world Englishes among students taking SSLL subject and those who have not taken the subject. The results have shown that there are different attitudes towards world Englishes between NNSE students who have taken SSLL subject and those who have not. Unlike studies conducted by Yoshikawa (2005), the present study does not find any significant difference in attitudes towards Inner Circle English among SSLL students and non-SSLL students. The results show that the involvement in SSLL subject is not the only factor that may cause different attitudes towards world Englishes.

Furthermore, the present study also attempts to identify different attitudes towards world Englishes among NNSE students from LR majors and those from NLR majors. The results have demonstrated that the different attitudes are apparent between these categorizations. The majors which expose them to the knowledge of world Englishes (i.e., LR majors) contribute to the more positive attitudes towards world Englishes. NLR students showed more negative attitudes towards world Englishes in some aspects. Further research may need to use a larger sample size. Furthermore, interviews can be incorporated with the questionnaires to gain more profound insights into the informants' attitudes (Almegren, 2018). It is also possible to consider assessing different students' attitudes before and after taking similar subjects towards world Englishes. 
More modification of the statements in the questionnaire is necessary, for example in statement seven, in order to avoid different readings, which can result in deviance from expectation.

\section{About the Author:}

Aditya Nur Patria is a lecturer at the Applied Foreign Languages Department, Vocational College, Universitas Diponegoro, Indonesia. His research interests include sociolinguistics, second language learning, language attitudes, discourse analysis, and language use in workplaces. ORCid ID: https://orcid.org/0000-0001-5498-8921

\section{References}

Agheyisi, R., \& Fishman, J.A. (1970). Language attitude studies: a brief survey of methodological approaches. Anthropological Linguistics, 12(5), 137-157.

Al-Mutairi, M.A. (2020). Kachru's three concentric circles model of English language: an overview of criticism \& the place of Kuwait in it. English Language Teaching, 13(1), 8588. Retrieved from https://doi.org/10.5539/elt.v13n1p85

Almegren, A. (2018). Saudi students' attitude towards world Englishes. International Journal of Applied Linguistics \& English Literature, 7(4), 238-247. Retrieved from http://dx.doi.org/10.7575/aiac.ijalel.v.7n.4p.238

Amin, N. (1997). Race and Identity of the Nonnative ESL Teacher. TESOL Quarterly, 31(3), 580-83. Retrieved from https://doi.org/10.2307/3587841

Bolton, K. (2009). Varieties of World Englishes. In B. B. Kachru, Y. Kachru, \& C. L. Nelson (Eds.), The Handbook of World Englishes (pp.289-312). West Sussex: Wiley-Blackwell.

Bruthiaux, P. (2003). Squaring the circles: Issues in modeling English worldwide. International Journal of Applied Linguistics, 13(2), 159-178. Retrieved from https://doi.org/10.1111/1473-4192.00042

Crystal, D. (2003). English as a global language (2 ${ }^{\text {nd }}$ ed.). Cambridge: Cambridge University Press.

da Rosa, E. N. (2017). Linguistic variation in English. Revista de Letras, 19(25), 35-50. Retrieved from https://doi.org/10.3895/rl.v19n25.4523

Department of Education and Training. (2018, June 8). 2017 First Half Year Higher Education Statistics. Retrieved from https://www.dese.gov.au/download/4124/2017-first-half-yearstudent-data-summary-infographics/6105/document/pdf

Dewi, A. (2014). Perception of English: A Study of Staff and Students at Universities in Yogyakarta, Indonesia. Newcastle upon Tyne: Cambridge Scholars Publishing.

Dörnyei, Z. (2007). Research Methods in Applied Linguistics. New York: Oxford University Press.

Ferguson, C. A. (1992). Foreword. In B. B. Kachru (Ed.), The Other Tongue: English across Cultures ( $2^{\text {nd }}$ ed., pp. vii-xi). Urbana: University of Illinois Press.

Gerritsen, M \& Nickerson, C. (2009). BELF: Business English as a lingua franca. In F. Bargiella-Chiappini (Ed.), The Handbook of Business Discourse (pp. 180-192). Edinburgh: Edinburgh University Press.

Kachru, B.B. (1985). Standards, codification, and sociolinguistics realism: The English language in the outer circle. In R. Quirk, \& H. Widdowson, (Eds.), English in the World: Teaching and Learning of Language and Literature (pp. 11-30). Cambridge: Cambridge University Press. 
Kim, Y. S. (2007). Korean Adults' Attitudes towards Varieties of English, (Unpublished Master's thesis). The University of Edinburgh, UK. Retrieved from https://www.era.lib.ed.ac.uk/handle/1842/1903

Lippi-Green, R. (2012). English with an Accent ( $2^{\text {nd }}$ ed.). London: Routledge.

Mahboob, A., \& Elyas, T. (2014). English in the Kingdom of Saudi Arabia. World Englishes: journal of English as an international and intranational language, 33(1), 128-142. Retrieved from https://doi.org/10.1111/weng.12073

Marlina, R. (2013). Globalisation, internationalisation, and language education: an academic program for global citizens. Multilingual Education, 3(5), 1-21.

Matsuda, A. (2003). Incorporating world Englishes in teaching English as an international $\begin{array}{llll}\text { language. } & \text { TESOL } & \text { Quarterly, } & \text { 719-729. }\end{array}$ from https://doi.org/10.1093/elt/46.4.340

McKenzie, R. M. (2010). The Social Psychology of English as a Global Language: Attitudes, Awareness and Identity in the Japanese Context. New York: Springer.

Medgyes, P. (1992). Native or non-native: Who's worth more? ELT Journal, 46(4), 340-49. Retrieved from https://doi.org/10.1093/elt/46.4.340

Medgyes, P. \& Kiss, T. (2019). Quality assurance and the expatriate native speaker teacher. In J. D. M. Agudo (Ed.), Quality in TESOL and Teacher Education: From a Results Culture Towards a Quality Culture (pp. 94-102). New York: Routledge.

Mollin, S. (2006). Euro English. Assessing Variety Status. Tübingen: Gunter Narr.

Passakornkarn, S., \& Vibulphol, J. (2020). Development of world Englishes-based listening materials to raise the awareness of the varieties of English for Thai upper secondary school students. LEARN Journal: Language Education and Acquisition Research Network Journal, 13(1), 225-246.

Phillips, V. (2017). The employability of non-native English speaking teachers: An investigation of hiring practices and beliefs in Australian adult ELT. English Australia Journal, 33(1), 3-27.

Phillipson, R. (1992). ELT: the native speaker's burden? ELT Journal, 46(1), 12-18. Retrieved from https://doi.org/10.1093/elt/46.1.12

Phillipson, R. (1996). Linguistic imperialism: African perspectives. ELT Journal, 50(2), 160167. Retrieved from https://doi.org/10.1093/elt/50.2.160

Rahman, M. S. (2017). The advantages and disadvantages of using qualitative and quantitative approaches and methods in language "testing and assessment" research: a literature review. Journal of Education and Learning, 6(1), 102-112. Retrieved from http://dx.doi.org/10.5539/jel.v6n1p102

Rampton, M. B. H. (1990). Displacing the 'native speaker': Expertise, affiliation, and inheritance. ELT Journal, 44(2), 97-101. Retrieved from https://doi.org/10.1093/eltj/44.2.97

Tan, C. (2005). English or Singlish? The syntactic influence of Chinese and Malay on the learning of English in Singapore. Journal of Language and Learning, 3(1), 156-179.

Tsuchiya, S. (2020). The native speaker fallacy in a US university Japanese and Chinese program. Foreign Language Annals, 53(3), 527-549. Retrieved from https://doi.org/10.1111/flan.12475

Ulum, Ö.G., \& Köksal, D. (2019). Ideological and Hegemonic Practices in Global and Local EFL Textbooks Written for Turks and Persians. Acta Educationis Generalis, 9(3), 66-88. 
Widdowson, H. G. (1994). The Ownership of English. TESOL Quarterly, 28(2), 377-80. Retrieved from https://doi.org/10.2307/3587438

Yano, Y. (2009). English as an international lingua franca: from societal to individual. World Englishes, 28(2), 246-55. Retrieved from https://doi.org/10.1111/j.1467971X.2009.01587.x

Yoshikawa, H. (2005). Recognition of world Englishes: Changes in Chukyo University students' attitudes. World Englishes, 24(3), 351-60. Retrieved from https://doi.org/10.1111/j.0083-2919.2005.00416.x

\section{Appendices}

Appendix

Questionnaire: Attitudes towards World Englishes

a. My home country:

b. Study program (e.g. Master of Applied Linguistics):

c. Are you taking/ Have you taken subject "Sociolinguistics and Language Learning"?

$\square$ Yes No

d. Have you ever been to English-speaking countries (except Australia, UK, USA, Canada, and New Zealand) for studying or travelling? Yes No

a. Studying: Name of country / length of stay $(\ldots \ldots \ldots \ldots \ldots \ldots \ldots \ldots . . . . . . \ldots \ldots \ldots \ldots \ldots)$

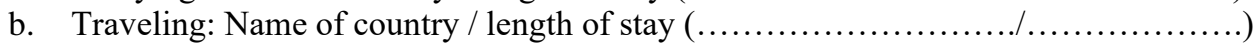

Circle the answer that reflects your opinion about the statements below.

Example:

I enjoy studying at this university.

Strongly Disagree Disagree Neutral Agree

Strongly Agree

1. English is the most popular language among language learners in your home country. This is natural in the present world situation.

Strongly Disagree Disagree Neutral Agree Strongly Agree

2. English has to be taught by native speakers.
Strongly Disagree
Disagree
Neutral Agree
Strongly Agree

3. English has to be taught by local teachers (non-native speakers).
Strongly Disagree
Disagree
Neutral Agree
Strongly Agree

4. Standard American English or Standard British English is the most suitable as a model language for learners in your home country.
Strongly Disagree
Disagree
Neutral Agree
Strongly Agree

5. Standard Singaporean English or Standard Indian English is suitable as a model language for learners in your home country.

Strongly Disagree Disagree $\quad$ Neutral Agree $\quad$ Strongly Agree

6. English variety from your home country (e.g., Chinese English, Japanese English, Indonesian English, Vietnamese English) is acceptable if it is communicable.
Strongly Disagree
Disagree
Neutral Agree
Strongly Agree

7. You had better avoid using idiomatic expressions in conversations in English with non-native speakers of English. Strongly Disagree Disagree Neutral Agree $\quad$ Strongly Agree

\section{CONFLICT OF INTEREST STATEMENT}

The author agrees that this research was conducted in the absence of any self-benefits, commercial or financial conflicts and declares the absence of conflicting interests with any funders. 